\title{
Studies on the Distribution and Characteristics of an Allochthonous Population of Acacia farnesiana
}

\author{
Agustín Naranjo Cigala ${ }^{* 1}$, Marcos Salas $^{2}$, Leila Agudo ${ }^{1}$, Elizabeth Fernández ${ }^{1}$ and José R. Arévalo ${ }^{3}$ \\ ${ }^{I}$ Departamento de Geografia, Facultad de Geografia e Historia, Universidad de Las Palmas de Gran Canaria, Las \\ Palmas de Gran Canaria 35003, Spain \\ ${ }^{2}$ Especies Invasoras: Grupo de Investigación Interinsular, Spain \\ ${ }^{3}$ Departamento de Ecología, Facultad de Biología, Universidad de La Laguna, La Laguna, 38206, Spain
}

\begin{abstract}
The Acacia farnesiana shrub species is native to Central America, but naturalized and considered an invasive species in many tropical and subtropical parts of the world. This study examines some of the characteristics of an Acacia farnesiana allochthonous population in the Canary Islands. When an alien species colonizes a new environment, it interacts with new elements to which is not accustomed: predators, pollinators, dispensers, competitors. To become successful these new elements need to fill all the species requirements. This paper attempts to determine the degree of resilience of this species and how dangerous can be for the native community. The information provided by this study is of maximum importance when deciding how dangerous this invasive species is, as well as determining how it should be handled and, where advisable, eradicated.
\end{abstract}

Keywords: Acacia farnesiana, distribution, allochthonous population, invasive plant.

\section{INTRODUCTION}

Acacia farnesiana, known in the Canary Islands as aromero, is considered an invasive species in several parts of the world [1-6]. In the Canary Islands, its existence as a cultivated species is documented as far back as the 18th Century [7, 8], but it was not considered as naturalized until well into the 20th Century [9, 10]. This species has rarely been mentioned in previous studies on exotic invasive species in the Canary Islands [11,12], while other species of the same genus, such as Acacia cyclops or Acacia saligna, were considered dangerous.

However, despite this lack of recognition as an invasive species, the populations of Acacia farnesiana on the island of Gran Canaria currently cover considerable surface areas (Fig. 1). They are not only found in anthropized places, spilling over from cultivated land and gardens, but are also consolidated in areas which are largely unaffected by human intervention, competing, at least for space, with autochthonous species and communities.

This situation has led us to deduce that the species has considerable potential for further spread. Information as to how it becomes established and progresses in those habitats in which it is most frequently found is therefore urgently required. To date, most of the places in which this plant has consolidated are riverbeds and gully sides, although in some areas, it has shown a more marked capacity to progress, occupying watersheds and flat areas between colonized riverbeds.

*Address correspondence to this author at the Edificio de Humanidades (Universidad de Las Palmas de Gran Canaria). C. Perez del Toro, 1, 35003 Las Palmas de Gran Canaria, Spain; E-mail: anaranjo@dgeo.ulpgc.es
The objectives of this study are to gain more in-depth knowledge about the dynamics, structure and habitat preference of this species in Gran Canaria. To this end, we have selected a population we believe to be significant, located in the Arguinenguín Gully (Barranco de Arguineguín), in the south of Gran Canaria.

\section{MATERIALS AND METHODOLOGY}

For this study, we selected the lower stretch of the Arguineguín Gully, at a height of between 40 and 110 metres above sea level. Human intervention has had little impact on this stretch so habitat factors alone are likely to explain its distribution. The tops of all plants were measured, as was the trunk diameter of each specimen. Where one sole trunk was not visible, the diameters of the main branches of the specimen were measured. The phenology and vegetative state (sapling, dead specimen, etc.) were recorded.. Sampling was started at the top of the chosen stretch of gully and the coordinates of the first specimen measured were taken using a GPS device. Once the position of this specimen had been recorded, the distance and direction to the nearest specimen was measured. Where the distances between specimens was great but the specimens were visible from the reference point, a telemeter was used, while the exact location of more distant specimens that were not visible was recorded using a GPS. Thus, the coordinates of all the specimens in the studied area were noted. Possible errors in the measuring process were corrected as far as possible by carrying out further checks in the field. Phenological observations were made over a three year period.

To determine the relation between the acacia population and environmental variables in the gully, the vegetation of the area was mapped. 


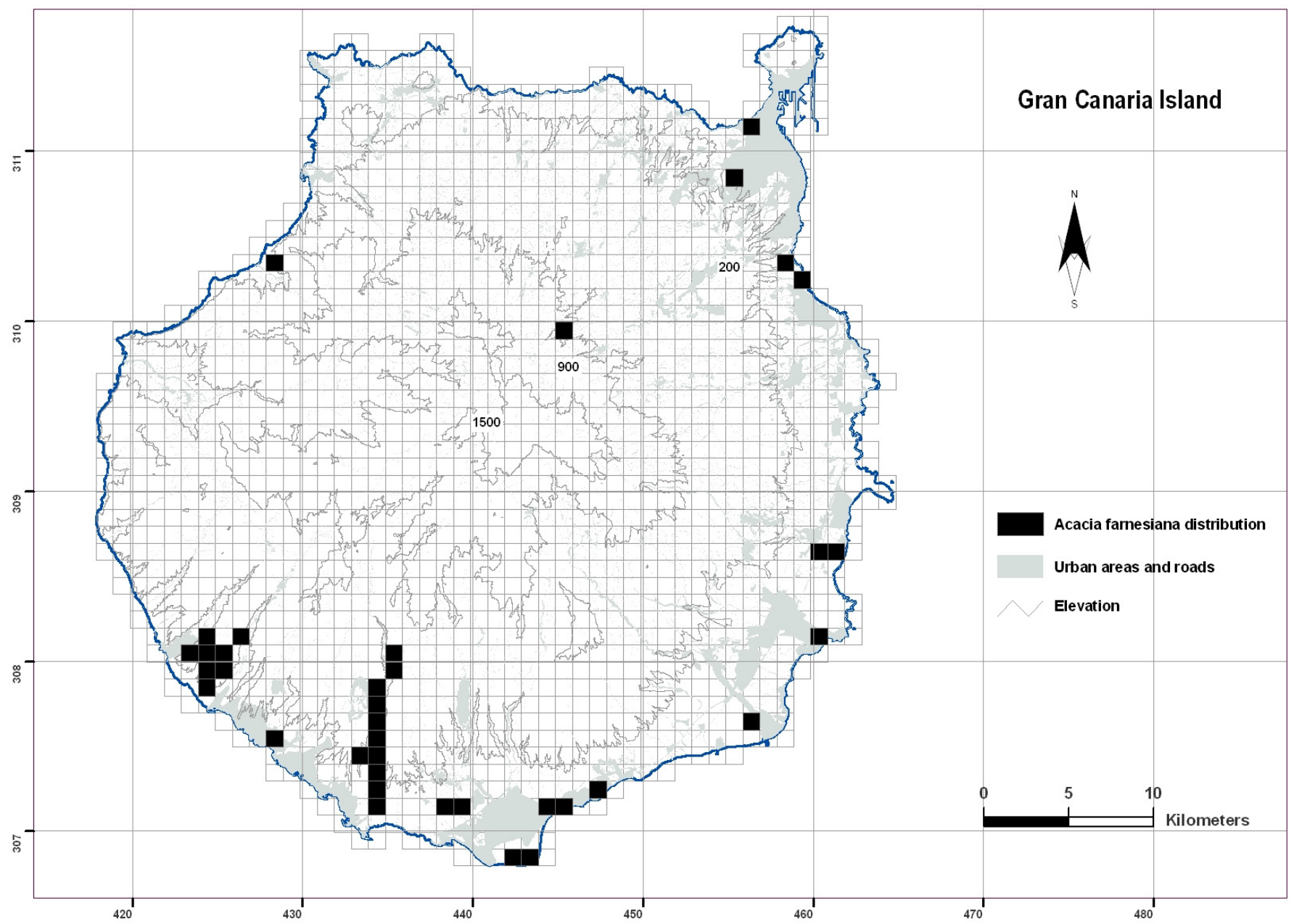

Fig. (1). Distribution of Acacia farnesiana on the island of Gran Canaria.

The following units were identified for mapping and analysis purposes:

- $\quad$ Permanent riverbed: characterized by the existence of an accumulation of boulders, and with scant presence of smaller materials. In this area water runs along the bed every year. The water is rich in carbonic salts that cover the boulders with a white layer, and in nitrogen salts derived from the eutrophitation of the waters that run along the gully. Vegetation is scant, due to the lack of soil, and is characterized by a wide range of nitrophilous species of Pegano-Salsoletea, (Rivas-Martínez \& al. 2001) as well as a large number of neophytes and other species that germinate easily in these conditions but rarely prosper. At some points, where water remains stagnant during long periods, reeds belonging to the Scirpo-Juncenion genus appear.

- Temporary riverbed: located on either side of the permanent riverbed. Water runs along this area less frequently, not necessarily every year, and with less intensity than along the permanent riverbed, resulting in an accumulation of sand and, subsequently, young soil. It is occasionally affected by rises in the river level in very rainy years. Its vegetation covering is much greater than that of the permanent riverbed, with abundant communities of cerrillo (LygeoStipetea; Hyparrhenietalia; Cenchro-Hyparrhenion), a set of perennial graminoids that give the area a savannah-like appearance. Chamaephyte nitrophilous species are also commonly found alongside these graminoids.

- Terrace edge: an area that presents a degree of accumulated clay and sand, which allows more abundant vegetation to consolidate. Given that it is an edge, and is also very stony, it is not suitable for cultivation and it has therefore not suffered the use given to the rest of the clayey terrace. This area is dominated by dwarf woodlands of tarajales (Tamarix canariensis), intermingled with reedbeds of Arundo donax.

- Clayey terrace: these are flat areas with accumulated clay and sand. In some cases they are used for agricultural purposes, while in others, agricultural activities have been abandoned. In any case, these areas have been affected by anthropogenic activities, and their vegetation has undergone numerous changes, dominated firstly by annual ephemeral weeds, and subsequently by perennial graminoids (Cenchrus ciliaris, Hyparrhenia sinaica), nitrophilous elements of Pegano-Salsoletea (Launaea arborescens, Schizogyne 
glaberrima), and finally turning into tabaiba communities (Euphorbia regis-jubae), rich in Kleinia-Euphorbietea species (Parolinia ornata, Kleinia neriifolia, Plocama pendula).

- $\quad$ Alluvia: located at the foot of the gully sides, and in contact with the vegetation that covers these sides, these areas have deep stony soil, with no carbonic salts or nitrogen. Their substantial vegetation is dominated by the balo (Plocama pendula), with sporadic tabaibas dulces (Euphorbia balsamifera) and even cardones (Euphorbia canariensis).

$\bullet$

Degraded alluvia produced by the construction of the road and other buildings (tanks, greenhouses, outbuildings, etc.) in the gully. Vegetation here is characterized by the significant presence of neophytes of tropical or subtropical origin: Nicotiana glauca, Ricinus communis, Datura innoxia, Argemone mexicana, etc.

Acacia farnesiana var. farnesiana was easily distinguishable from other similar species of the genus (Acacia schaffneri, Acacia pacensis and Acacia tortuosa) by the elliptic shape of its petiolar glands, obviously lenticellate twigs and to the size and shape of its fruit. It is also distinguishable from A. farnesiana var. guanacastensis by the number of leaf and leaflet partitions [13, 14]. Two exicattas belonging to specimens from this population are deposited in the TF herbarium, (numbers TFC 47974 and TFC 47975). Acacia farnesiana var. farnesiana shows little morphological variation on Gran Canaria, the only aspect that appears to vary at all is its habit, which is more or less squat, depending on the hydric resources available.

\section{RESULTS}

In the area studied, the population comprised 397 specimens of all ages, from seedlings just a few centimetres high to adult specimens of up to $5 \mathrm{~m}$. The specimens are dispersed at regular intervals along the whole riverbed. No one stretch of the riverbed presents either a noticeably different density, or a distribution by height that is markedly different from other areas (Fig. 2). The population is markedly uniform, making it impossible to identify any specific area as the starting point for the invasion. The phenological stages of Acacia farnesiana in Arguineguín Gully coincide with those of the other populations found to date on the island. The most notable phenological aspects identified are leaf production and flowering. In the bibliography consulted, we have only found information regarding flowering, as the documentation on leaf production merely mentions that the species is evergreen, and says nothing of any variation in foliage abundance during the course of the year. In Arguineguin Gully, leaves of $A$. farnesiana plants become more abundant in April, are very plentiful from June to October, start to fall in the autumn and for part of the winter, from October to March, the plants have considerably fewer leaves. We also observed that, in rainy years, the plants produce appreciably fewer leaves during January and February. The flowering of the species depends on the local climate, occurring from November to February in Puerto Rico, from December to March in Central America, from January to April in north-western India [15], while in the north of Mexico, flowering periods of February to May, and even July to February have been recorded [13]. Some plants in Arguineguin Gully always have a few flowers treat any time of the year. However, the most significant flowering takes place from December to March. Regular flowering, albeit minimal, ensures that dry and fresh flowers, as well as floral buds, can be observed on the trees at the same time.

As a result of this distribution in time, which can be seen in Fig. (3), the production of leaves does not coincide with flowering. Flowering takes place immediately after the first rains. The trees' fruit is formed in spring. Fruit remains green and barely visible until October-November, subsequently turning a dark greyish brown. The fruit continues to mature on the tree for several months, and finally falls a year after its first appearance. Thus, green fruit can be found on the same specimen as newly-matured fruit and fruit from previous years. The strategy of permanent, if minimal, flowering throughout the year enables the plant to make the most of sporadic or out-of-season rainfall to produce more flowers.

The specimens of Acacia farnesiana in the gully analyzed are not equally distributed throughout the different environmental units present in the studied area (Table 1). The clayey terrace edge has by far the highest number of acacia, 4.5 per $1,000 \mathrm{~m}^{2}$, followed by the temporary riverbed, with the much lower figure of 1.29 acacias per $1,000 \mathrm{~m}^{2}$. But this difference is even greater if we consider an area between these two, i.e., the contact area between the temporary riverbed and the terrace edge, the edge of the edge, where the density of acacias rises to 6.13 specimens per $1,000 \mathrm{~m}^{2}$. In order to analyze this intermediate area, which we have called T-R (terrace-riverbed), we took a $1 \mathrm{~m}^{2}$ strip along the contact area between each of the two units. This contact line between the riverbed and the terrace would appear to offer the best ecological qualities for the acacias to take root, as they seem not to encounter the difficulties posed in other environmental units. In the riverbed units, the limiting factors that would appear to affect the Acacia farnesiana population are the periodical floods and the lack of substrate, while in terraces and degraded areas, the competition of other dwarf shrub species and human activities seem to be the main factors that limit its presence. The increased presence of aromeros in this sector does not appear to be due to an increased ease of germination or recruiting, as the number of seedlings is not higher in the T$\mathrm{R}$ than in other parts of the gully, as Table 1 shows. Neither is this the area with the tallest specimens, as height appears to be a negative factor for the survival of acacias in areas affected by periodical flooding. Thus, the average height of the acacias is lower in the riverbed and surrounding area than in the terrace and degraded zones (Fig. 4).

Another interesting fact that is related to an extent to the environmental units is the distribution of seedlings in relation to the nearest stool plants. The analysis of this information is based on the fact that in the riverbed communities, the water running along the riverbed acts as a seed dispersal agent, at least sometimes. This factor could lead to a higher seed dispersal capacity along the riverbed, and consequently a bigger distance between the seedlings and the adult specimens in this environment. The data 


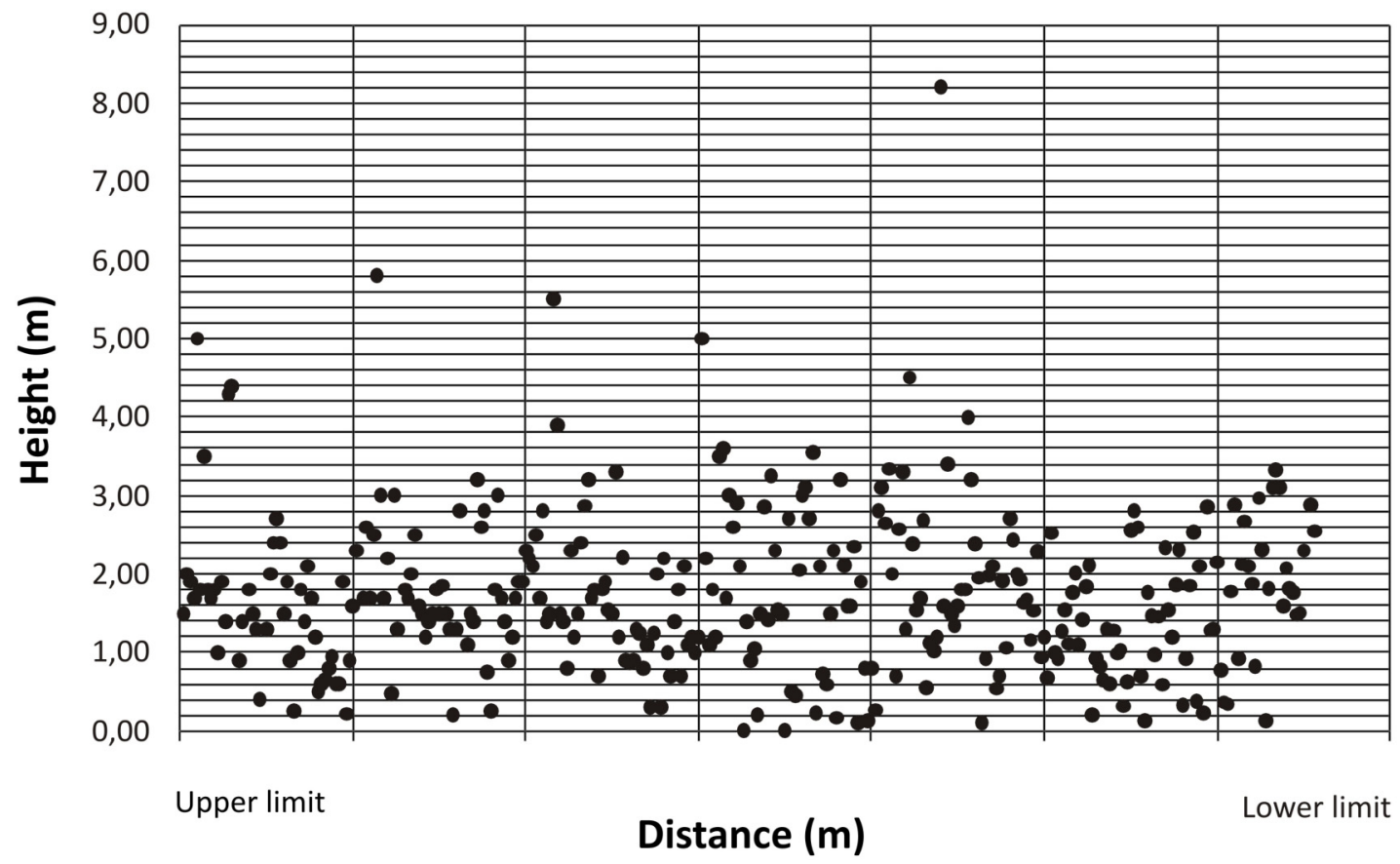

Fig. (2). Height of specimens along the gully.

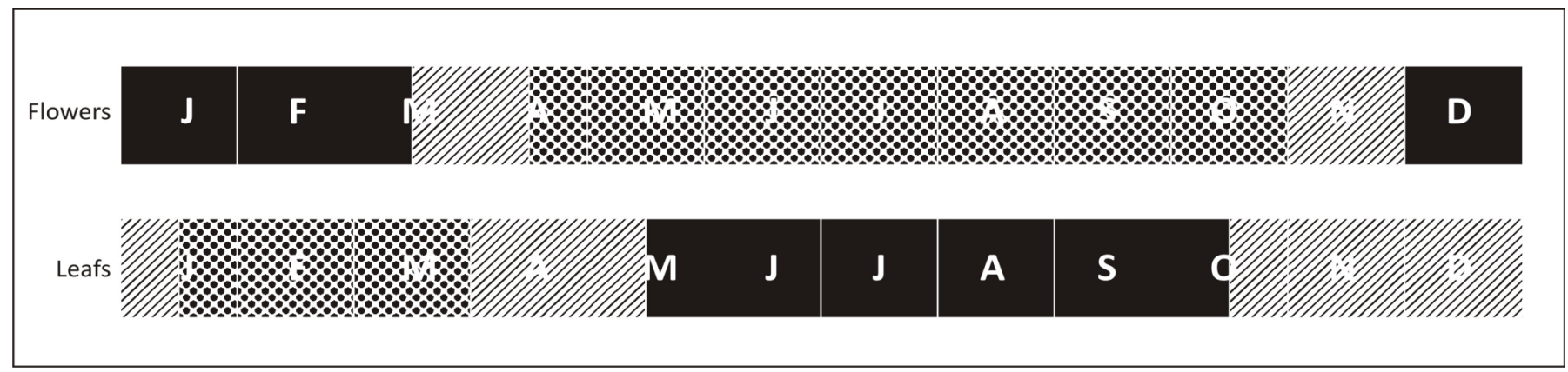

Fig. (3). Phenology of Acacia farnesiana in the Gully of Arguineguín. Black: months with more flowering and formation of leaves, stripe: months with presence of both structures and dotted: periods of negligible presence of flowers or leaves.

regarding the distance of these seedlings from the nearest adult is shown in Table 2 .

As we can see from the Table and from Fig. (5), there are no particular differences between the two environmental units. Both reveal seedlings between 1 and $10 \mathrm{~m}$ from the stool plants, with sporadic gaps in which the young plants may be more than $20 \mathrm{~m}$ from the adults. This homogeneity indicates that, if the water acts as a dispersal agent in the riverbed, there must be at least one seed dispersal agent in the terrace. In this case, seeds may be dispersed by animals: rabbits, lizards, birds, etc.

Table 1. Number of Acacias Present in an Environmental Unit Compared with the Unit's Surface Area

\begin{tabular}{|c|c|c|c|c|c|c|}
\hline Alluvium & 9.00 & $82,790.32$ & 0.11 & 0.00 & 0.00 & 2.08 \\
\hline Terrace edge & 177.00 & $39,336.68$ & 4.50 & 12.00 & 6.78 & 1.70 \\
\hline Riverbed & 31.00 & $98,679.82$ & 0.31 & 2.00 & 6.45 & 1.70 \\
\hline Clayey terrace & 52.00 & $335,762.12$ & 0.15 & 7.00 & 13.46 & 1.91 \\
\hline Total & 397.00 & $788,226.42$ & 6.50 & 34.00 & 46.49 & 1.78 \\
\hline T-R (Terrace-riverbed) & 76.00 & 12.40 & 6.13 & 7.00 & 9.21 & 1.62 \\
\hline
\end{tabular}




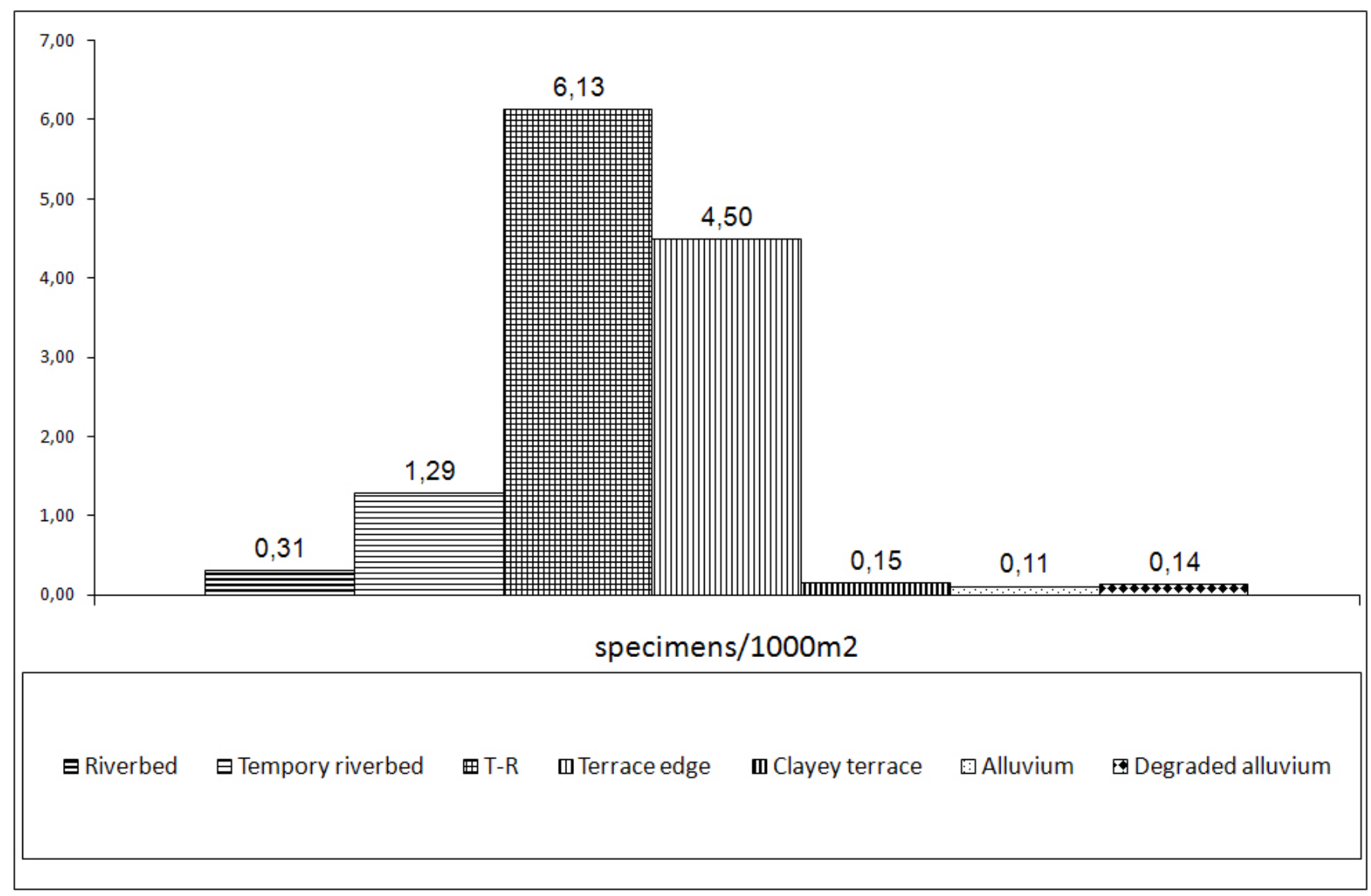

Fig. (4). Distribution of acacia specimens in the different environmental units analyzed.

Table 2. Number and Distance of the Seedlings from the Nearest Adult

\begin{tabular}{|c|c|c|c|c|c|}
\hline Unit & Surface Area & $\mathbf{N}^{\mathbf{0}}$ of Seedlings & Seedlings/1.000 $\mathbf{~ m}^{2}$ & Average Distance (m) & Average Height (m) \\
\hline \hline Riverbed & $181,470.14$ & 13.00 & 0.072 & 8.005 & 0.42 \\
\hline Terrace & $375,098.80$ & 19.00 & 0.051 & 9.720 & 0.34 \\
\hline Alluvium & $148,867.16$ & 2.00 & 0.013 & -- & - \\
\hline
\end{tabular}

The height data of the acacias in the Gully of Arguineguín reveal little difference between all the environmental units. Most of the acacias are between 0.5 and $2.5 \mathrm{~m}$ high. The only noteworthy aspects here are the absence of acacias over $3.5 \mathrm{~m}$ high in the permanent riverbed, clearly a result of the elimination of acacias in periodical flood events; the greater average height of acacias in the clayey terrace, and the high proportion of short acacias in the border area between the terrace edge and the temporary riverbed (T-R area). The proportion of acacias by height class is given in Table $\mathbf{3}$.

\section{DISCUSSION}

The characteristics of the Acacia farnesiana allochthonous population present in the Gully of Arguineguín enable us to deduce some aspects that will serve to give us more in-depth knowledge of the specific nature of this plant and of its population dynamics. Although we do not know exactly when this plant was introduced into this area, we can deduce that it is currently a young population, uniformly dispersed along the whole of the sector of the gully we studied.

Unlike natural populations, in this aloctonous population the species has adapted to the presence of recurrent floods, which implies the disappearance of the tallest individuals, maintaining a lower average height of the population individuals. The height of individuals is therefore a factor in selecting them. Its phenology allows us to deduce a strong link between the flowering season and that of leaf production, an important factor in the determination of its possible use as forage. The long periods that the fruit remains on the plant enable several generations of fruit to coexist on the plant at the same time, and this facilitates the predation of Mimosestes mimosae, a brucid beetle, on its seeds. This fact would appear to indicate some relationship between the insect's activity and the reproductive biology of the acacia. A different phenological pattern of the species in various parts of the world demonstrates its plasticity to adapt to new environments. 
Table 3. Proportion of Acacias by Height Class in the Environmental Units

\begin{tabular}{|c|c|c|c|c|c|c|c|c|c|c|c|c|c|}
\hline Height Class (m) & 0 - 0,5 & $0,5-1$ & $1-1,5$ & $1,5-2$ & $2-2,5$ & $2,5-3$ & $3-3,5$ & $3,5-4$ & $4-4,5$ & $4,5-5$ & $5-5,5$ & $5,5-6$ & $6-8,5$ \\
\hline Terrace edge & 5.12 & 13.70 & 29.10 & 23.10 & 12.80 & 8.55 & 3.40 & 0.85 & 0.85 & 0.85 & 0.00 & 0.85 & 0.85 \\
\hline Temp. Riverbed & 11.94 & 22.40 & 16.40 & 23.90 & 8.96 & 7.46 & 4.50 & 2.99 & 0.00 & 0.00 & 1.49 & 0.00 & 0.00 \\
\hline Perm. Riverbed & 7.41 & 18.50 & 18.50 & 14.80 & 22.20 & 14.80 & 3.70 & 0.00 & 0.00 & 0.00 & 0.00 & 0.00 & 0.00 \\
\hline Terrace & 10.00 & 14.00 & 12.00 & 22.00 & 16.00 & 16.00 & 6.00 & 2.00 & 0.00 & 2.00 & 0.00 & 0.00 & 0.00 \\
\hline$T-R$ & 21.62 & 13.50 & 24.30 & 16.20 & 5.41 & 10.80 & 2.70 & 5.41 & 0.00 & 0.00 & 0.00 & 0.00 & 0.00 \\
\hline Total & 9.73 & 16.10 & 21.80 & 21.50 & 12.40 & 10.40 & 4.00 & 2.01 & 0.34 & 0.67 & 0.34 & 0.34 & 0.34 \\
\hline
\end{tabular}

The apparent uniformity of the population does not hold up if we analyze the presence of acacias in the different environments of the gully. Thus, we see that the area where the plant best consolidates is the strip where the riverbed meets the terraces with accumulated clay. This preference is indubitably related to the plant's need for water and light. Acacia farnesiana is a shade-intolerant species [15] and therefore struggles among the tall scrubs on the terrace, although our data indicate that the seedling production in this area is very similar to that of the riverbed. However, the plants in the contact area do not have the same bearing as those growing on the terraces, as periodical floods wash away the tallest specimens. It may be that the roots of this acacia do not go deep enough to withstand the water pressure, unlike the bigger autochthonous species that grow alongside it (Plocama pendula and Tamarix canariensis). These autochthonous species also generate layers and continue to progress, even once they have fallen over.

The average height of the specimens in the population, $1.78 \mathrm{~m}$, would appear to indicate that this is a young population, as its average height in its places of origin is from 3 to $5 \mathrm{~m}$ [13]. This uniformity, despite the youth of the population, could indicate particularly rapid propagation.

The fact that fruit remains on the plant for several seasons favors the presence of a brucid beetle (Mimosestes mimosae), which perforates the legumes of the acacia and, although this point is still being studied, may favor the plant's seed germination. Thus, when the adult brucid emerges from the old pods, there will be young fruit on the same plant that it can use to lay its eggs. If, when the insect emerged, there were no green fruit available, the life cycle of the animal would be affected. The fact that the plant appears to favor the use of its fruit by an insect may point to a possible mutual benefit in this animal-plant interaction.

The presence of seed dispersal agents, in both the riverbed and the terraces, would appear to be demonstrated by the uniform distribution of the seedlings with respect to the stool plants (see Fig. 5). If seeds in the riverbed are dispersed by hidrochory, then there must be dispersal agents in the clayey terraces and alluvia, presumably acting by zoochory. In their natural location, endozoochory, dispersal of Acacia farnesiana by the iguana Ctenosaura similis is known [16].

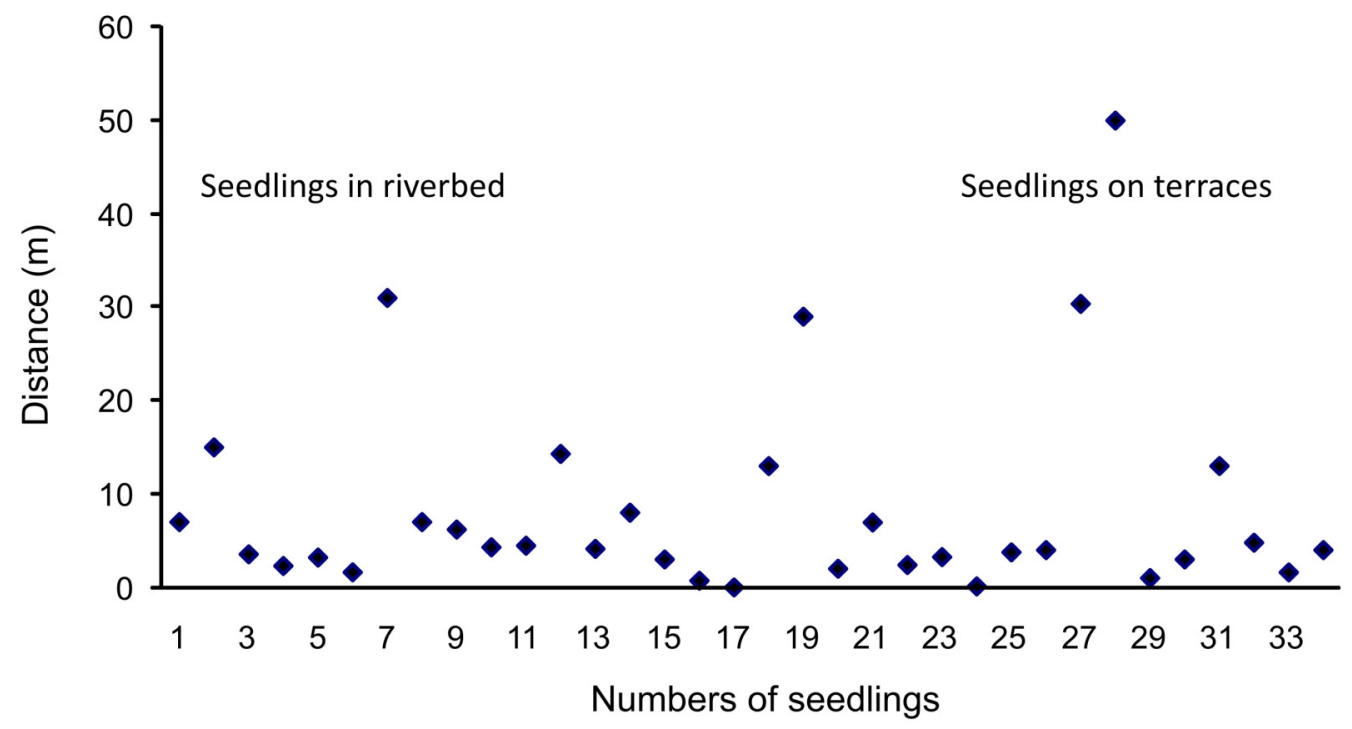

Fig. (5). Distance, in meters, between seedlings and stool plants in the riverbed and the clayey terrace. 
Our study has added to knowledge about how this plant lives, establishes and disperses in the Arguineguín Gully, and in riverbeds of similar characteristics. Such knowledge will be of use if and when this plant needs to be controlled, and will also help us to determine the most suitable way to eradicate the species, causing the least impact. The capacity of the plant to adapt to new situations involving a new territory with new competitors, new environmental factors, is essential to achieve a permanent and effective colonization. Acacia farnesiana has demonstrated this ability, so its eradication will be very difficult.

\section{ACKNOWLEDGEMENTS}

This work is the part of the study program of exotic species carried out by the Invasive Species: Interinsular Research Group (EIGI) of the University of La Laguna and University of Las Palmas de Gran Canaria. We thank the " Consejería de Educación, Cultura y Deportes, Gobierno de Canarias"' (Regional Government Department of Education, Culture and Sports) for providing funding for this project (Code: PI042004/096). We thank the students of Geography of University of Las Palmas de Gran Canaria for their assistance in the sampling, and Heather Adams of University of Las Palmas de Gran Canaria for translating it into English.

\section{NOMENCLATURE}

Izquierdo I, Martín JL, Zurita N, Arechavaleta M. Lista de especies silvestres de Canarias (hongos, plantas y animales terrestres): Gobierno de Canarias, Santa Cruz de Tenerife; 2004.

Rivas-Martínez S, Fernández-González F, Liodi J, Lousa M, Penas A. Syntaxonomical checklist of vascular plant communities of Spain and Portugal to association level. Itinera Geobotánica 2001; 14: 5-341.

\section{REFERENCES}

[1] Tutin TG, Ed. Flora Europea 5. London: Cambridge University Press 1980.
[2] Stone CP, Smith CW, Tunison JT, Eds. Alien plant invasions in native ecosystems on Hawaii: management and research. Honolulu: University of Hawaii Press, University of Hawaii Cooperative National Park Research Studies Unit 1992.

[3] Waterhouse DF. The major invertebrate pests and weeds of agriculture and plantation forestry in the Southern and Western Pacific. Canberra: The Australian Centre for International Agricultural Research 1997.

[4] Meyer JY. Preliminary review of the invasive plants in the Pacific islands (SPREP Member Countries). In: Sherley G, Ed. Invasive species in the Pacific: A technical review and draft regional strategy. Samoa, South Pacific Regional Environment Programme 2000; p. 93.

[5] Xiangyun Z. Acacia farnesiana. In: Li ZY, Xie Y, Eds. Invasive Alien Species in China. Beijing: China Forestry Publishing House 2002; p. 243

[6] Batianoff GN, Butler DW. Assessment of Invasive naturalized plants in south-east Queensland. Appendix. Plant Prot Q 2002; 17: 27-34.

[7] Viera Y, Clavijo J. Diccionario de Historia Natural de las Islas Canarias. Índice alfabético descriptivo de sus tres reinos: animal, vegetal y animal (1731-1813). Santa Cruz de Tenerife: Nivaria Ediciones 2005.

[8] Bory de Saint-Vincent JBGM. Ensayos sobre las Islas Afortunadas y la antigua Atlántida o compendio de la Historia General del Archipiélago Canario: JADL, La Orotava 1988.

[9] Lems K. Phytogeographic Study of the Canary Islands. Thesis ined, University of Michigan; USA 1958.

[10] Kunkel G. Notes on the introduced elements in the Canary Island's Flora. In: Kunkel G Ed. Biogeography and Ecology in the Canary Islands. La Haya: Junk 1976; pp. 249-66.

[11] Sanz-Elorza M, Dana ED, Sobrino E. Aproximación al listado de plantas vasculares alóctonas invasoras reales y potenciales en las islas Canarias. Lazaroa 2005; 26: 55-66.

[12] Kunkel G. Aliens to the Canary Flora. Part I. Trees and shrubs. Cuad Botánica Canaria 1969; 5: 27-44.

[13] Clarke HD, Seigler DS, Ebinger JE. Acacia farnesiana (Fabaceae: Mimosoideae) and related species from Mexico, the southwestern U.S. and the Caribbean. Syst Bot 2002; 14: 549-64.

[14] Ebinger JE, Seigler DS, Clarke HD. Notes on the Segregates of Acacia farnesiana (L.) Willd. (Fabaceae: Mimosoideae) and Related Species in North America. Southwest Nat 2002; 47: 86-91.

[15] Parrota JA. The role of plantations forests in rehabilitating degraded tropical ecosystems. Agri Ecosyst Environ 1992; 41: 11533.

[16] Traveset A. Ctenosaura similis Gray (Iguanidae) as a Seed Disperser in a Central American Deciduous Forest. Am Midland Nat $1990 ; 123: 402-4$ 